\title{
Gérald Sandy, «Lex commentandi»: Philippe Béroalde et le commentaire humaniste
}

\section{Filippo Fassina}

\section{Q OpenEdition \\ 1 Journals}

\section{Edizione digitale}

URL: http://journals.openedition.org/studifrancesi/9145

DOI: ERREUR PDO dans /localdata/www-bin/Core/Core/Db/Db.class.php L.34 : SQLSTATE[HYO00]

[2006] MySQL server has gone away

ISSN: 2421-5856

\section{Editore}

Rosenberg \& Sellier

\section{Edizione cartacea}

Data di pubblicazione: 1 juin 2008

Paginazione: 171

ISSN: 0039-2944

\section{Notizia bibliografica digitale}

Filippo Fassina, «Gérald Sandy, «Lex commentandi»: Philippe Béroalde et le commentaire humaniste», Studi Francesi [Online], 154 (LII | I) | 2008, online dal 30 novembre 2015, consultato il 07 janvier 2021. URL: http://journals.openedition.org/studifrancesi/9145 ; DOI: https://doi.org/ERREUR PDO dans / localdata/www-bin/Core/Core/Db/Db.class.php L.34 : SQLSTATE[HY000] [2006] MySQL server has gone away

Questo documento è stato generato automaticamente il 7 janvier 2021.

\section{(c)}

Studi Francesi è distribuita con Licenza Creative Commons Attribuzione - Non commerciale - Non opere derivate 4.0 Internazionale. 
Gérald Sandy, «Lex commentandi»: Philippe Béroalde et le commentaire humaniste

Filippo Fassina 


\section{NOTIZIA}

GÉRALD SANDY, «Lex commentandi»: Philippe Béroalde et le commentaire humaniste, «Bibliothèque d'Humanisme et Renaissance», LXIX, 2 (2007), pp. 399-423.

Il presente studio analizza le caratteristiche generali dei commenti approntati da Filippo Beroaldo alle opere latine, nel caso specifico, l'Asinus aureus di Apuleio. Dopo una breve parentesi biografica, incentrata sull'esperienza nell'Università di Bologna, l'A. fornisce alcuni esempi del metodo impiegato da Beroaldo e ne sottolinea l'enorme erudizione che, tuttavia, non diventa mai pedante grazie alla varietas di informazioni e digressioni offerte al lettore, che spaziano dalla filologia al diritto, dalla letteratura all'antropologia. Anche l'uso delle fonti e delle citazioni è sapientemente dosato. Successivamente, vengono spiegate le motivazioni che hanno portato Beroaldo a scegliere come soggetto del proprio lavoro l'Asinus aureus: oltre allo stile, è l'intento morale sottostante all'opera che maggiormente interessa al commentatore. L'A. non manca di sottolineare anche le critiche che Beroaldo muove ad Apuleio, soprattutto riguardo ad alcune interpretazioni lessicali, ma tali critiche - anche quelle nei confronti di altri autori antichi - non sono mai violentemente polemiche, ma sempre mitigate e supportate da motivazioni teoriche. In conclusione, questo contributo intende segnalare la grande erudizione di Beroaldo, autore fortunatissimo nella cultura francese, grazie alla quale il commentatore poté soddisfare i gusti sia dei dotti, sia dei colti, sia degli studenti, rendendo attuale Apuleio come modello per svariate discipline all'interno della cultura universitaria bolognese. 